\title{
Functional properties of the human ventral mesencephalic neural stem cell line hVM1
}

\author{
Jan Tønnesen ${ }^{\mathrm{a}, 1}$, Emma Gonzalez Seiz ${ }^{\mathrm{b}+1}$, Milagros Ramos ${ }^{\mathrm{b}}$, Olle Lindvall ${ }^{\mathrm{c}}$, \\ Alberto Martinez-Serrano ${ }^{b}$, Merab Kokaia ${ }^{a+*}$ \\ a Experinental Epilepsy Group. Wallenberg Neuroscience Center, Lund University Hospital, 221 84, Lund, Sweden

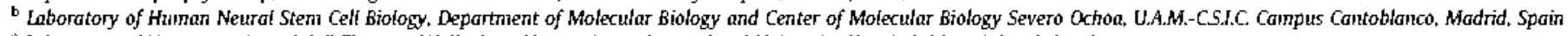 \\ "Laboratory of Neurogenesis and Cell Therapy, Wallenberg Neuroscience Center, Lund University Hospital, 221 84, Lund, Sweden
}

\section{Keywords:}

A B S T R A C T

Huinan neural stein cell

Dopaminergic neuron

In vitro

Electrophysiology

Functional properties

Diflerentiation

Parkinson's disease

The human fetal ventral mesencephalon-derived stem cell line, hvM1, yields high number of tyrosine hydroxylase-expressing presumed dopaminergic neurons upon in vicro diflerentiation. Here we report that cells generated from this line differentiate into a neuronal phenotype, express electrophysiological properties of functional neurons and respond to neurotransmitters in vitro. However, the electrophysiological properties are immature and the cells require longer maturation time than possible under in virro conditions.

Clinical trials with intrastriatal transplantation of human fetal mesencephalic tissue in patients with Parkinson's disease (PD) have provided proof-of-principle that grafted dopaminergic neurons can reinnervate the denervated striatum, release dopamine, become functionally integrated in host neural circuitries, and in some cases give rise to substantial clinical improvement (Lindvall and Bjorklund, 2004). The quest for a stem cell source has been ongoing ever since in order to provide sufficient quantities of standardized, transplantable dopaminergic neurons to implement clinically competitive cell replacement therapy for PD. Immortalized human neural stem cell lines are suitable model systems for studying genetic and epigenetic influences on stability over passages, and on stem cell proliferation and differentiation in vitio and in vivo. Their advancage is multipotency within the neural lineage, expandability and stabilicy, making them available over practically indefinite periods of time (Martinez-Serrano et al., 2001; Villa et al., 2002, 2004; Kim, 2007). Several studies have described amelioration of behavioral deficits by grafting such immorcalized human stem cells in rodent models of neurological disease (Lee et al., 2007), and have characterized their immunocytochemical and biochemical features. However, few studies have addressed the functional properties of human neural stem cell lines (Jung et al., 1998; Cho et al., 2002; Lotharius et al., 2002; De Filippis et al., 2007; Donato et al., 2007), most of them failing to demonstrate

\footnotetext{
* Corresponding author.

E-mail address: merab.kokaia@neurol.lu.se (M. Kokaia).

$1 \pi$ and EGS contributed equally to this study.
}

maturation of these cells into neurons that can generate full-blown action potentials (Jung et al., 1998; Cho et al., 2002; De Filippis et al., 2007; Donato et al., 2007).

We recently reported on a newly derived human fecal ventral mesencephalic stem cell line, hVM1, that generates high fractions of dopaminergic cells, even after considerable expansion (>10 passages) (Villa et al., 2009). The hVM1 cell line was subjected to thorough biochemical, genetic, and immunocytochemical characterization to document its usefulness as a model for developing clinically competent cell lines for PD (Villa et al., 2009). Here we have explored the functional properties of hVM1 cells in vitro, based on calcium imaging and electrophysiological investigations. Interestingly, using electrophysiological whole-cell patch-clamp measurements, we found neuronal properties in more than half of all recorded cells, including immature action potentials and membrane rectification. We observed generation of mature spontaneous action potentials in one cell. Calcium imaging demonstrated that hVM1 cells, which have differentiated to neurons, are responsive to glutamate, dopamine and $G A B A$, as expected for ventral mesencephalic neurons.

The derivation of the hVM1 cell line was previously described in detail (Villa et al., 2009). Briefly, cells were isolated from the ventral mesencephalic region of a dead, aborted human fetus, aged 10 weeks, at Lund Universicy Hospital, according to guidelines approved by the Lund/Malmö Ethical Committee. Cells were immorcalized by infection with a retroviral vector coding for $v$-myc (LTR-vmyc-SV40p-Neo-LTR) (Villa et al., 2000) generating the hVM1 polyclonal cell line (Villa et al., 2009). 
Cells were expanded as atcached cultures on poly-L-lysine (PLL, $10 \mu \mathrm{g} / \mathrm{ml}$ )-coated dishes in N2 supplemented DMEM/F12 medium in the presence of $20 \mathrm{ng} / \mathrm{ml}$ of each of EGF and bFGF (Villa et al., 2009). To induce differentiation of the cells, bFGF and EGF were withdrawn from the medium and human recombinant glial cell line-derived neurotrophic factor (GDNF, $2 \mathrm{ng} / \mathrm{ml}$, Peprotech) and dibucyryl-cAMP (1 $\mu \mathrm{M}$, Sigma) were added (Lotharius et al., 2002; Riaz et al., 2002). After plating on PLL-coated glass coverslips for differentiation $\left(10^{5}\right.$ cells $/ \mathrm{cm}^{2}$ ), cells were kept in proliferation medium for $24 \mathrm{~h}$ before changing to differentiation medium. All culturing was done at $37^{\circ} \mathrm{C}$ and $95 \%$ humidity in a low oxygen atmosphere $\left(5 \% \mathrm{O}_{2}, 5 \% \mathrm{CO}_{2}\right)$. For all experiments, we used hVM1 cell line at passage 11 to 12 .

For immunocytochemical analysis, 4\% PFA-fixed samples were incubated overnight with primary antibodies against: $\beta$-III-tubulin (1:1000, monoclonal, Sigma), Glial Fibrillacy Acidic Protein (GFAP; $1: 1000$, monoclonal, Sigma) and cyrosine hydroxylase (TH; $1: 1000$, polyclonal, Chemicon). Cells were then incubated with the secondary antibody for $30 \mathrm{~min}$. Cell nuclei were counterstained with To-Pro (1:500; Invitrogen). Specificities of secondary antibodies were confirmed by parallel immunoscainings without the primary antibody.

For calcium imaging experiments, cells were loaded with $10 \mu \mathrm{M}$ Fura-2 AM (Molecular Probes) for $30 \mathrm{~min}$ at $37^{\circ} \mathrm{C}$ in HBSS medium added $5.55 \mathrm{mM}$ glucose and 0.02\% Pluronic F-127 (Molecular Probes), and washed for $20 \mathrm{~min}$ in HBSS medium. Next, coverslips were mounted in a perfusion chamber on the microscope stage at $37^{\circ} \mathrm{C}$ as described in Ruiz et al. (1998). Single cell analysis of the changes in cytosolic calcium concentration $\left(\left[\mathrm{Ca}^{2+}\right]_{i}\right)$ was expressed as the ratio of Fura-2 fluorescence intensity at 340 and $380 \mathrm{~nm}$ excitation. Different neurotransmitters and potassium were added as a bolus at the indicated times and at the following concentrations (arrows in Figs. 1D, G, L): $100 \mu \mathrm{M}$ dopamine (Sigma); $100 \mu \mathrm{M} \gamma$-aminobutyric acid (GABA, Tocris Cookson); $100 \mu \mathrm{M}$ glutamate (Sigma). The concentrations of drugs and potassium are within the range previously reported to elicit cytosolic calcium release in calcium imaging experiments (Jung et al., 1998; Malmersjo et al., 2009). Cells were washed with Mgfree HBSS medium and supplemented with $30 \mu \mathrm{M}$ of glycine just prior to the addition of glutamate. Two selective receptor antagonists were used: 5-methyl-10,11-dihydro-5-dibenzocyclohepten-5,10-imine maleate (MK-801; $50 \mu \mathrm{M}$; Tocris Cookson) for blocking glutamate receptors (NMDA subcype) and picrotoxin (PTX: $100 \mu \mathrm{M}$; Tocris Cookson) for blocking $\mathrm{GABA}_{\mathrm{A}}$ receptors. For $\mathrm{KCl}$-induced depolarization of cells, the recording chamber was perfused with an isosmotic HBSS solution containing $60 \mathrm{mM} \mathrm{KCl}$ (Supplementary figure 1).

Functional properties of differentiated stem cells were evaluated by the whole-cell patch-clamp technique as described previously (Parish. Castelo-Branco et al. 2008). In short, coverslips with differentiated cells were transferred to a recording chamber continuously perfused at a rate of $3 \mathrm{ml} / \mathrm{min}$, at room temperature, with carbogenated $\left(95 \% \mathrm{O}_{2} / 5 \% \mathrm{CO}_{2}\right)$ artificial cerebrospinal fluid (aCSF) containing: $\mathrm{NaCl} 119 \mathrm{mM} ; \mathrm{KCl} 2.5 \mathrm{mM} ; \mathrm{MgSO}_{4} 1.3 \mathrm{mM} ; \mathrm{CaCl}_{2} 2.5 \mathrm{mM}$; $\mathrm{NaHCO}_{3} 26.2 \mathrm{mM}$; $\mathrm{NaH}_{2} \mathrm{PO}_{4} 1 \mathrm{mM}$; glucose $11 \mathrm{mM}$ (300 mosm, pH 7.4). Patch-clamp recording pipette tip resistances were 3.5-5 $\mathrm{M} \Omega$ when filled with solution containing $\mathrm{K}$-gluconate $122.5 \mathrm{mM} ; \mathrm{KCl}$ $17.5 \mathrm{mM}$; $\mathrm{NaCl} 8 \mathrm{mM}$; KOH-HEPES $10 \mathrm{mM}$; KOH-EGTA $0.2 \mathrm{mM}$; MgATP $2 \mathrm{mM}$; and $\mathrm{Na}_{3}$ GTP $0.3 \mathrm{mM}$ (295 mOsm, pH 7.2). Resting membrane potential was measured in current clamp mode at $0 \mathrm{pA}$. Input resistance was assessed from $5 \mathrm{mV}$ square voltage pulses at RMP. For $\mathrm{I} / \mathrm{V}$ curves, we measured the membrane potential, while injecting 500 ms positive or negative currents stepwise (Figs. $1 \mathrm{M}, \mathrm{N}$ ).
Whole-cell currents and voltages were amplified by a patch-clamp amplifier (EPC10; HEKA Elektronik).

All data are presented as mean \pm standard error of the mean (SEM). Comparisons of parameters within the cell lines were done by Student's $t$-test, and analysis for temporal changes within the cell lines by linear regression. Level of significance was set at $p<0.05$.

Expression of the neuronal marker $\beta$-III-tubulin and the dopaminergic marker $\mathrm{TH}$ reached maximum after 12 days under differentiation conditions, and was observed in $19.7 \pm 1.6 \%$ and $12.1 \pm 1.0 \%$ of the total number of cells, respectively. The GFAP + glial cell population at this stage of differentiation constituted $2.9 \pm 0.3 \%$ of all cells (Supplementary figure $1 \mathrm{~A}-\mathrm{C}$ ). After 30 days of differentiation, the percentage of $\mathrm{TH}$-expressing cells decreased compared to 12 days to $7.4 \pm 0.4 \%$, while the percentage of GFAP + cells increased to $5.6 \pm$ $0.4 \%$. The fraction of $\beta$-[Il-tubulin expressing cells remained stable at 30 days (21.2 $\pm 1.7 \%$ of the total population) and did not differ from that at 12 days (Figs. $1 \mathrm{~A}-\mathrm{C}$ ).

After 12 days of differentiation, application of $60 \mathrm{mM}$ potassium increased intracellular calcium in $9.5 \pm 2.4 \%$ of cells (Supplementary figure 1D-F). Application of $100 \mu \mathrm{M}$ dopamine elicited a calcium increase in $8.8 \pm 1.9 \%$ of cells, while $9.6 \pm 2.7 \%$ and $7.3 \pm 1.7 \%$ of cells responded to $100 \mu \mathrm{M}$ glucamate and $100 \mu \mathrm{M}$ GABA, respectively (Figs. 1D-L), already after 7 days of differentiation. Glutamate responses were blocked by the NMDA receptor antagonist MK-801, and GABA responses by the $G_{A B A_{A}}$ receptor antagonist PTX (Figs. 1D, J), confirming receptor specificity.

Using whole-cell patch-clamp recordings at later stages of differentiation (between 20 and 32 days), we found that 37 out of 54 recorded cells (68\%) displayed active membrane properties suggestive of an immature neuronal phenocype (Fig. 1N). Sixteen cells (43\%) fired immature action potentials upon current injections. Over the differentiation period, there was a significant decrease in resting membrane potential (RMP) assessed as linear regression and with $t$ test, from $-65.4 \pm 4.5 \mathrm{mV}$ at days $20-21(n=8)$ to $-41.6 \pm 7.3 \mathrm{mV}$ at day 32 ( $n=9$; Figs. $1 Q, R$ ). This was not accompanied by significant changes in input resiscance $\left(R_{\mathrm{j}}\right.$ ) (assessed by linear regression and $t$ test), the average value at days $20-21$ being $2029 \pm 353(n=8)$ and at day 32 being $3003 \pm 425(n=8$; Fig. 1T). We further compared the current-volcage $(I-V)$ relationship of the recorded cells at days 20-23 with those at days 31-32. There was clearly less inward rectification during application of hyper- and depolarizing pulses to the membrane in the cells at days 31-32 of differentiation, as compared to days 20-22 (Fig. 1R). Among 16 cells exhibiting passive membrane properties (Fig. 1M), we observed a significant decrease in RMP, from $-86.4 \pm$ $0.76 \mathrm{mV}$ at days $20-22(\pi=10)$ to $-75.8 \pm 3.7 \mathrm{mV}$ at days $29-32$ ( $\pi=4$; Fig. 1P). The $R_{i}$ was unaltered in these cells over time, being $69.6 \pm 14.6 \mathrm{M} \Omega$ at days $20-22(n=10)$ and $75.4 \pm 19.0 \mathrm{M} \Omega$ at days $29-$ 32 ( $n=4$, Fig. 1S). The nominally high resting membrane potential, the lack of rectification and the low $R_{\mathrm{i}}$ indicate that these cells have acquired glial-like properties.

The hVM1 cell line is able to survive in differentiation medium for more than 30 days, and from days $20-32$ of differentiation more than half of the cells expressed neuronal electrophysiological properties, including membrane rectification and immacure action potential firing. In one cell, we observed spontaneous action potentials that increased in frequency upon current injection-induced depolarization. These findings provide evidence that expanded immortalized human fetal neural stem cells sustain their molecular identity to acquire neuronal properties, and that differentiation can be achieved in vitno. It should

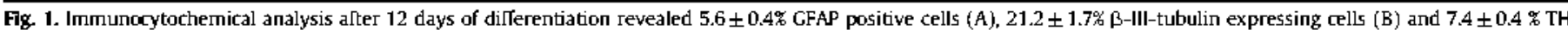

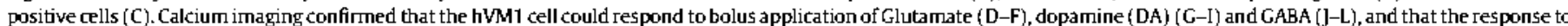

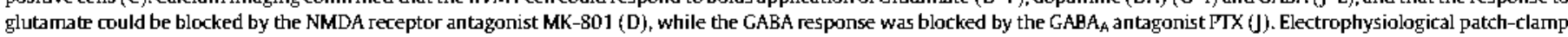

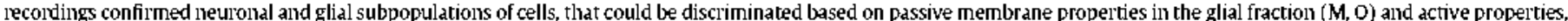

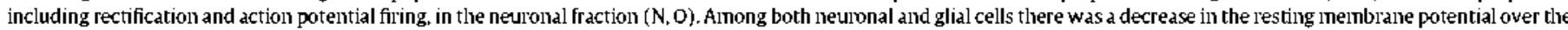

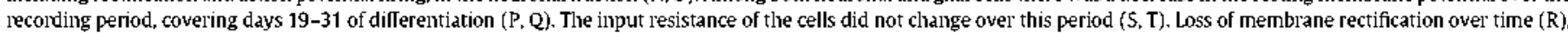

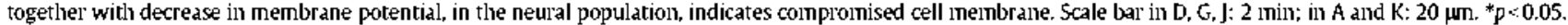



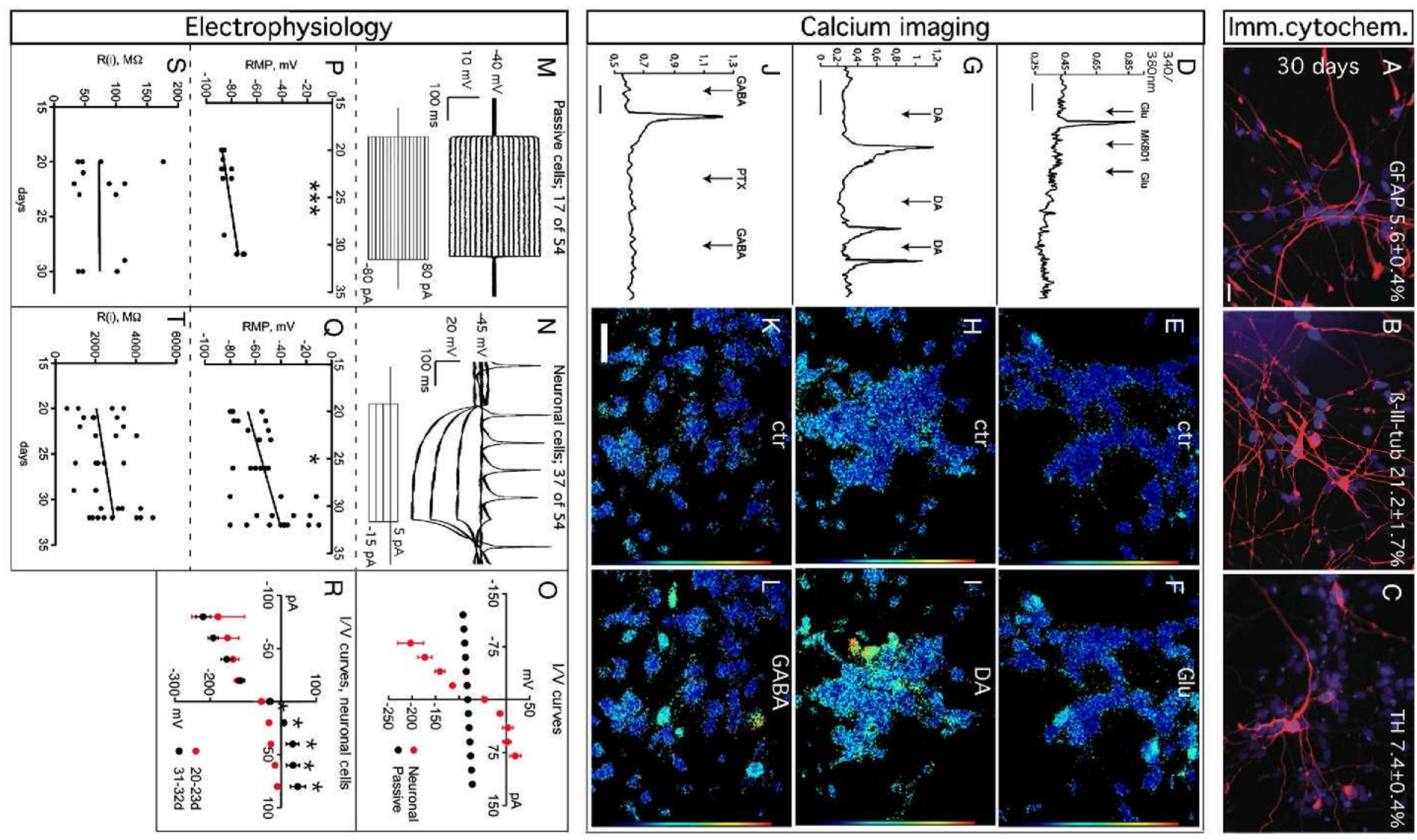
be noted, though, that we did not observe post-synaptic currents in any of the recorded cells under the present conditions, indicating that no functional synaptic connections between cells had been established.

Our finding that maximum expression of $\beta$-IIl-tubulin occurs after 12 days and is unchanged after 30 days of differentiation corcoborates the original report describing the immunocytochemical properties of the hVM1 cell line (Villa et al., 2009). In this previous report we additionally confirmed expression of an array of midbrain dopaminergic markers, including GIRK2, Calretinin, DAT, VMAT2, ADH2, Lmx1a, Lmx1b, Pitx3, Nurr-1, En1, Mash1 and Ngn2, pointing to a subscantia nigral profile of these cells (Villa et al., 2009).

Over the reported time period, we observed a relative increase in GFAP-expressing glial cells and decrease in the fraction of $\mathrm{TH}$ expressing cells. These data indicate a loss of TH-expressing catecholaminergic neurons and possibly also other mature neurons, concomitant with the increase in the glial population. The decline in percencage of neurons was also suggested by the electrophysiological data, showing a reduction of RMP among both neuronal and passive cells over time, accompanied by a decrease in inward rectification in the neuronal population, indicating a compromised cell membrane. The gradual loss of membrane integrity likely reflects shortcomings in the in vitro culturing conditions.

More than half of the recorded cells expressed immature neuronal properties. This neuronal fraction is substantially higher than that estimated based on the presented immunocytochemical data ( $20 \%$ of cells express $\beta$-III-tubulin), and from calcium imaging data (7-10\% of cells respond to glutamate, dopamine or GABA). This discrepancy could be due to bias in visually choosing cells with more neuronal appearance for patch-clamp recordings. However, it could also reflect higher sensitiviry of the electrophysiological approach, compared to immunocytochemistry, as a method for evaluating neuronal differentiation.

We found that GABA application, similar to glutamate, induced calcium inflow into the cells. Normally, GABA hyperpolarizes neurons, driving the membrane potential away from what would activate voltage-dependent calcium channels (Rabow et al., 1995). However, in immature neurons, GABA acts as depolarizing transmitter due to higher chloride concentration inside the cells as compared to outside (Cherubini et al., 1991; Rivera et al., 1999). This was apparently the case in our experiments with calcium imaging

Dopamine can depolarize or hyperpolarize neurons through D1 and D2 metabotrobic receptors, respectively. The D2 receptors are expressed on nigral dopaminergic neurons mediating autoinhibition (Lacey et al., 1989). Recent experiments have demonstrated D2 autoreceptor activation induces intracellular calcium release in human embryonic stem cell-derived dopaminergic neurons at all stages of maturation (Malmersjo et al., 2009). Therefore, it is likely that the observed increase in intra-cellular calcium of hVM1 cells in response to dopamine application is a D2-mediated response in dopaminergic neurons. Alternatively, it can be a D1 receptor mediated response in non-dopaminergic neurons, expressing D1 receptors. Further studies are needed to elucidate the expression and function of dopamine receptor subtypes in hVM1 cells.

The hVM1 cell line may become useful for generating dopaminergic, and possibly other rypes of neurons, for experimental cell therapy approaches. It should be pointed out, though, that $v$-myc immortalization of these cells is compromising with respect to their potential clinical applications (Nilsson and Cleveland, 2003). Our data provide evidence that the multipotent hVM1 human ventral mesencephalic stem cell line is capable of differentiating into functional neurons, although under the present in vitro conditions with relatively immature properties. It was not possible to retrospectively identify recorded cells as dopaminergic under the current conditions. However, our previous immunocytochemical daca show that $47 \%$ of $\beta$-IIl-tubulin expressing cells were TH-positive, i.e., presumably dopaminergic (Villa et al., 2009). Therefore, it is reasonable to suggest that a considerable fraction of the recorded cells with immature neuronal properties were dopaminergic. Future in vivo studies, enabling longer survival times, and the development of human dopaminergic reporter constructs, e.g. human-TH-GFP, will shed light on the question whether these cells can differentiate to fully mature and functional ventral mesencephalic dopaminergic neurons.

\section{Acknowledgments}

This publication was supported by the European Community's Seventh Framework Programme grants Excell (Nr. 214706) and NeuroStemcell (Nr. 22943). Work at AMS group was supported by grants from Spanish Ministry of Science and Innovation (BIO200766807 and PLE2009-0101) and Carlos III Institute of Health (RETICS TerCel RD06/0010/0009). The Institutional grant from Foundation Ramón Areces to the Center of Molecular Biology Severo Ochoa (CBMSO) is also gratefully acknowledged.

\section{Appendix A. Supplementary data}

Supplementary data associated with this article can be found, in the online version, at doi:10.1016/j.expneurol.2010.01.013.

\section{References}

Cherubini, E., Gaiarsa, l.L., et al., 1991. GABA: an excitatory transmitter in early postnatal life. Trends Neurosci. 14 (12), 515-519.

Cho. T., Bae, J.H., et al., 2002. Human neural stem cells; electroplysiological properties of voltage-gated ion channels. Neuroreport $13(11), 1447-1452$.

De Filippis, L., Lamorte, G, et al., 2007. A novel, imınoltal, and inultipotent human neural stem cell line generating functional neurons and oligodendrocytes. Stem Cells 25 (9), 2312-2321.

Donato, R., Miljan, E.A., et al., 2007, Differential development of neuronal physiological responsiveness in two human neural stem cell lines. BMC Neurosci. 8, 36.

Jung. M., Kramer, E.M., et al., 1998. Novel pluripotential neural progenitor lines exhibiting rapid controlled differentiation to neurotransmitter receptor-expressing neurons and glia. Eur. J. Neurosci. 10 (10), 3246-3256.

Kim, S.U., 2007. Genetically engineered human neural stem cells for brain repair in neurological diseases. Brain Dev. 29 (4), 193-201.

Lacey, M.G. Mercuri, N.B., et al., 1989. Two cell types in rat substantia nigra zona compacta distinguished by membrane properties and the actions of dopamine and opioids. J. Neurosci. 9 (4), 1233-1241.

Lee, H.J., Kim, K.S., et al., 2007. Brain transplantation of immortalized human neural stem cells promotes functional recovery in mouse intracerebral hemorrhage stroke model. Stein Cells 25 (5), 1204-1212.

Lindvall, O., Bjorklund, A., 2004. Cell therapy in Parkinson's disease. NeuroRx 1 (4), 382-393.

Lotharius, J., Barg, S., et al., 2002. Effect of mutant alpha-synuclein on dopanine homeostasis in a new human mesencephalic cell line. J. Biol. Chem. 277 (41), 38884-38894.

Malmersjö, S., Liste, I., Dyachok, O., Tengholm, A, Arenas, E., Uhlen, P., 2009. Ca2+ and cAMP signaling in human embryonic stem cell-derived dopamine neurons. Stem Cells and Developinent (Electronic publication ahead of print). doi: $10.1089 / \mathrm{scd} .2009 .0436$.

Martinez-Serrano, A, Rubio, F.J., et al., 2001. Human neural stem and progenitor cells: in vitro and in vivo ploperties, and potential for gene therapy and cell replacement in the CNS. Curr. Gene Ther, 1 (3), 279-299.

Nilsson, JA, Cleveland, J.L., 2003. Myc pathways provoking cell suicide and cancer. Oncogene 22 (56), 9007-9021.

Parish, C.L. Castelo-Branco, G., et al., 2008. Wht5a-treatrd midbrain neural stem cells improve dopamine cell replacement therapy in parkinsonian mice. J. Clin. Invest. 118 (1), 149-160.

Rabow, L.E., Russek, S.]., et al., 1995. From ion currents to genomic analysis: recent advances in GABAA receptor research. Synapse 21 (3). 189-274.

Riaz, S.S., Jauniaux, E., et al., 2002. The controlled conversion of human neural progenitor cells derived fiom foetal ventral mesencephalon into dopaminergic neurons in vitro. Brain Res. Dev. Brain Res, 136 (1), 27-34.

Rivera, C., Voipio, J., et al., 1999. The $\mathrm{K}+/ \mathrm{Cl}-$ co-transporter $\mathrm{KCC} 2$ renders GABA liyperpolarizing during neuronal inaturation. Nature 397 (6716), 251-255.

Ruiz, F., Alvarez, G., et al., 1998. Protection by pyruvate and malate against glutamateinediated neurotoxicity. Neuroreport 9 (7), 1277-1282.

Villa, A., Liste, I., et al., 2009. Generation and properties of a new human ventral mesencephalic neural stem cell line. Exp. Cell Res. 315 (11) 1860-1874.

Villa, A., Navarto, B., et al., 2002. Genetic pelpetuation of in vino expanded human neural strm cells: cellular properties and therapeutic potrntial. Brain Res. Bull. 57 (6), 789-794

Villa, A., Navarro-Galve, B., et al., 2004. Long-term molecular and cellular stability of human neural stem cell lines. Exp. Cell. Res. 294 (2), 559-570.

Villa, A, Snyder, E.Y., et al., 2000. Establishment and properties of a growth factordependent, perpetual neural stem cell line from the human CNS. Exp. Neurol. 161 (1), 67-84. 